\title{
Pulmonary arterial hypertension associated with fenfluramine exposure: report of 109
}

\section{cases}

\author{
R. Souza*, M. Humbert*, B. Sztrymf*, X. Jaïs*, A. Yaïci*, J. Le Pavec*, F. Parent*, \\ P. Hervé*, F. Soubrier ${ }^{\#}$, O. Sitbon* and G. Simonneau*
}

ABSTRACT: The aim of the present study was to describe a large cohort of fenfluramineassociated pulmonary arterial hypertension (fen-PAH) and its possible prognostic markers.

The records of all patients with a diagnosis of fen-PAH evaluated at the present authors' centre from 1986-2004 were retrospectively studied. Baseline clinical and haemodynamic data were collected, as well as survival times.

The median duration of fenfluramine exposure was 6 months, with a median of 4.5 yrs between exposure and onset of symptoms. Nine (22.5\%) out of $\mathbf{4 0}$ patients evaluated resulted positive for the presence of germline bone morphogenetic protein receptor (BMPR) type 2 mutations. In these patients, the duration of exposure to fenfluramine was significantly lower than in patients without mutation. The median survival was $6.4 \mathrm{yrs}$, without significant difference between fen-PAH and a control group of idiopathic and familial pulmonary arterial hypertension patients referred to the present authors' centre during the same time frame and treated identically. Duration of fenfluramine exposure showed no relation to survival, while cardiac index was the only independent predictor of multivariate analysis.

Fenfluramine-associated pulmonary arterial hypertension shares clinical, functional, haemodynamic and genetic features with idiopathic pulmonary arterial hypertension, as well as overall survival rates. Therefore, the present authors conclude that fenfluramine exposure characterises a potent trigger for pulmonary arterial hypertension without influencing its clinical course.

KEYWORDS: Bone morphogenetic protein receptor type 2, fenfluramine derivatives, idiopathic pulmonary arterial hypertension, pulmonary arterial hypertension, survival

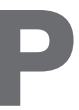

ulmonary arterial hypertension $(\mathrm{PAH})$ is a rare condition in which the main feature is the presence of increased pulmonary vascular resistance resulting in right heart failure and, ultimately, death [1]. In recent years, the understanding of $\mathrm{PAH}$ pathophysiology has allowed the recognition of multiple risk factors and associated conditions that trigger and/or worsen the progression of the disease [2, 3]. Germline mutations of the gene encoding bone morphogenetic protein receptor $(B M P R)$ type 2 are certainly clear examples of established risk factors for PAH development [4].

In the late 1960s, an increased incidence of severe PAH cases took place in Austria, Germany and Switzerland. Of newly diagnosed patients, $>60 \%$ had a history of intake of the anorexigen

For editorial comments see page 232. aminorex fumarate [5]. The fact that the epidemic started 2 yrs after aminorex fumarate became commercially available and disappeared 2 yrs after the drug was withdrawn, allowed the recognition of temporal and geographic relationships between the use of the drug and $\mathrm{PAH}$ development [6]. Although this clearly indicated a role as a risk factor, the clinical course of aminorex-associated PAH was not conclusively different from idiopathic PAH (IPAH, formerly known as primary pulmonary hypertension), despite later results suggesting a better survival in the first group [7]

In the early 1980s, the first descriptions of a possible relationship between the use of fenfluramine derivatives and PAH were published [8]. Following this, a retrospective study [9] reinforced the possible role of fenfluramine derivatives as risk factors for PAH development and the results of the International Primary Pulmonary
AFFILIATIONS

*Université Pains-Sud, UPRES-EA 2705 Pneumology Dept and French National Reference Centre for Pulmonary Hypertension, Antoine Béclère Hospital, Clamart and, and *Laboratory of Oncogenetics and Molecular Angiogenetics, Federation of Genetics, Pitié-Salpêtrière Hospital Group, Pierre and Marie Curie University, Paris, France.

CORRESPONDENCE

M. Humbert

Centre des Maladies Vasculaires

Pulmonaires

UPRES EA 2705

Service de Pneumologie et Réanimation Respiratoire Hôpital Antoine Béclère Assistance Publique - Hôpitaux de Paris

Université Paris-Sud.

157 rue de la Porte de Trivaux 92140 Clamart

Paris

France

Fax: 33146303824

E-mail: marc.humbert@abc.aphp.fr

Received:

August 112007

Accepted after revision:

October 092007

STATEMENT OF INTEREST

None declared. 
Hypertension Study (IPPHS) [10] conclusively demonstrated a strong association between $\mathrm{PAH}$ and the use of anorexic drugs (mainly derivatives of fenfluramine). Fenfluramine derivatives share with aminorex such characteristics as being potent serotonin (5-HT) uptake inhibitors and interacting directly with the 5-HT transporter [11]. 5-HT levels are known to be elevated in PAH [12] and 5-HT acts as growth factor for pulmonary artery smooth muscle cells $[13,14]$, thus possibly contributing to the pathophysiology of PAH development and progression. This suggests a possible pathway by which the use of fenfluramine derivatives might be linked to PAH.

The relationship between fenfluramine-derivative use and PAH was further confirmed in a recent study [15]. However how much this exposure influences the course of the disease, even after its interruption, is still matter of debate. RICH et al. [16] compared the outcome of a small group of 10 patients with fenfluramine-associated PAH (fen-PAH) with that of 70 patients with idiopathic PAH (IPAH). The results suggested that fen-PAH patients had worse survival rates when compared with IPAH patients [16].

The aim of the present study was to describe the clinical presentation of a large cohort of 109 patients with fen-PAH as well as to analyse the disease's possible prognostic markers in terms of long-term survival, characterising the fen-PAH story in France 10 yrs after the drug's withdrawal.

\section{METHODS}

\section{Patients}

The medical records of all patients with the diagnosis of fen-PAH that were evaluated at the present authors' centre from 1986-2004 were retrospectively studied. PAH was defined as a mean resting pulmonary artery pressure $>25 \mathrm{mmHg}$ with a pulmonary artery occlusion pressure $<15 \mathrm{mmHg}$, invasively assessed by rightheart catheterisation. Patients were classified as having been exposed to fenfluramine derivatives if the exposure occurred before the beginning of PAH symptoms. All fen-PAH had history of fenfluramine-derivative intake (including fenfluramine and dexfenfluramine) alone or in association with amphetamine-like agents. For comparison, the present authors also assessed baseline data and survival of all patients with idiopathic and familial PAH (I/FPAH, formerly known as primary pulmonary hypertension) [17] referred to the present authors' centre during the same time frame and treated identically. Although PAH treatment strategies varied during the period of study, no different approach was adopted in fenfluramine-derivative use so that all PAH patients were exposed to the same treatment regimen according to drug availability [1].

\section{Functional and haemodynamic evaluation}

All demographic data were collected from baseline evaluation, including New York Heart Association (NYHA) functional class assessment. After 1993, all patients performed an unencouraged 6-minute walk test (6MWT), as previously described [18]. Standard right-heart catheterisation and acute vasodilator challenge were performed in all patients for diagnostic confirmation. Patients were classified as acute responders according to the criteria recently described by SITBON et al. [19].

\section{Genetic studies}

In the period from 2000-2004, 40 patients with fen-PAH were assessed for BMPR2 germline mutation, as previously described [20]. The results of this assessment were partially published by HUMBERT et al. [21] in 2002. The duration of exposure was compared between patients with and without $B M P R 2$ mutations in order to test whether the duration of exposure to fenfluramine differed in genetically predisposed patients.

\section{Statistical analysis}

All continuous data are presented as mean \pm SD or median (interquartile range) as appropriate. Comparison between continuous data was performed using an unpaired t-test. A Chi-squared test was used for categorical data comparison. The Kaplan-Meier method was used to estimate survival

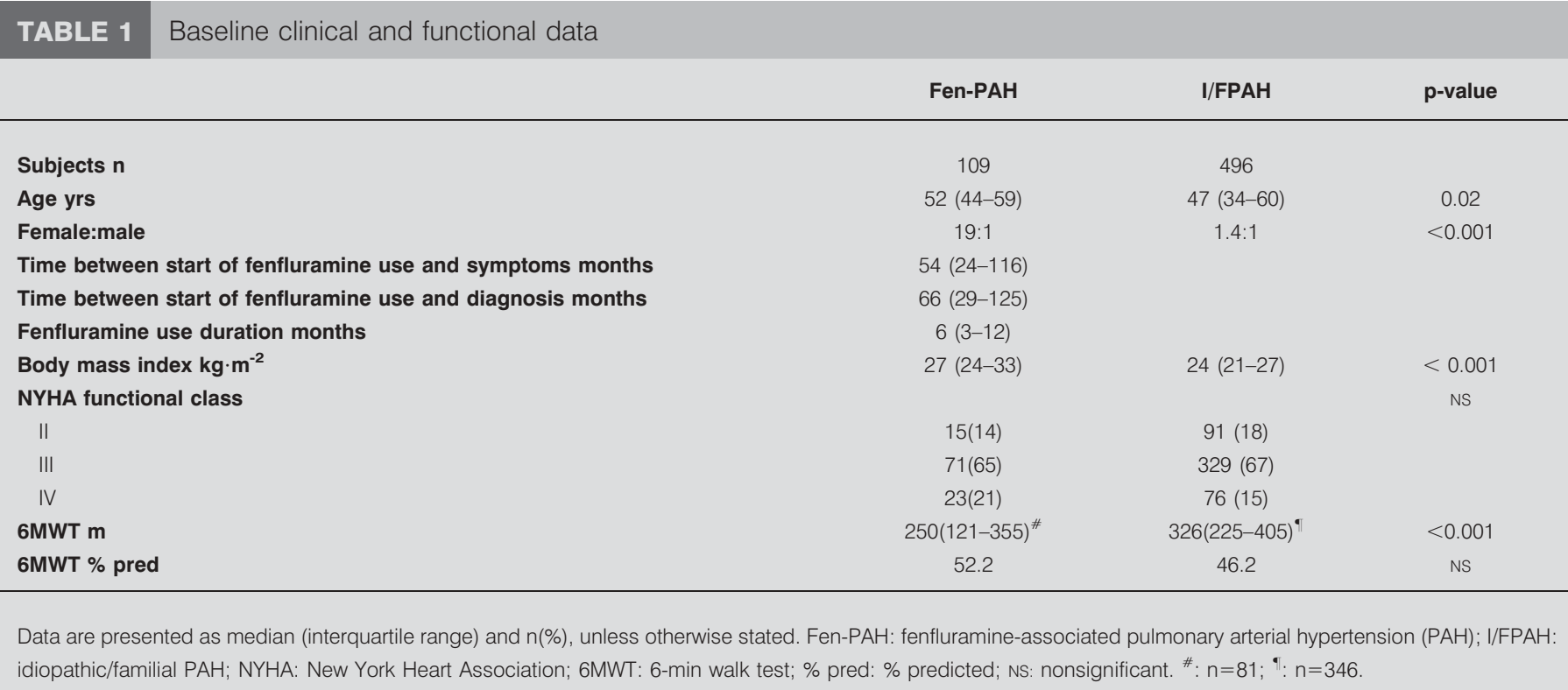


TABLE 2 Baseline haemodynamic data

\begin{tabular}{|c|c|c|c|}
\hline Right atrial pressure $\mathrm{mmHg}$ & $11 \pm 6$ & $10 \pm 5$ & NS \\
\hline Pulmonary artery occlusion pressure $\mathrm{mmHg}$ & $9 \pm 3$ & $9 \pm 3$ & NS \\
\hline Cardiac index L $\cdot \min ^{-1} \cdot \mathrm{m}^{-2}$ & $2.2 \pm 0.6$ & $2.3 \pm 0.7$ & NS \\
\hline Indexed pulmonary vascular resistance $\mathrm{U} \cdot \mathrm{m}^{-2}$ & $30 \pm 11$ & $29 \pm 12$ & NS \\
\hline
\end{tabular}

Data are presented as mean \pm SD and \% (95\% confidence interval) unless otherwise stated. Fen-PAH: fenfluramine-associated pulmonary arterial hypertension (PAH) IPAH: idiopathic PAH; Ns: nonsignificant.

status and the log-rank test was used for survival distribution comparison. Since NYHA functional class at baseline has been shown to be related to long-term survival in IPAH [22, 23], patients' outcome was described according to their functional class at baseline. Survival of fen-PAH was also compared with survival of IPAH and FPAH patients evaluated at the present authors' centre during the same period of observation (historical control).

Univariate analysis based on the Cox proportional-hazards model was used to examine the effect on survival of selected demographic, medical history, exercise capacity and haemodynamic variables assessed at baseline. Multivariate models were constructed using the variables of interest identified at univariate analysis. Proportional-hazards assumption was assessed for all variables of interest. Results were expressed as hazard ratios with $95 \%$ confidence intervals (CIs).

\section{RESULTS}

In the period 1986-2004, a total of 109 patients with fen-PAH and 496 patients with I/FPAH were evaluated at the present authors' centre. Baseline clinical and functional data are presented in table 1, showing a markedly higher proportion of female patients and a higher body mass index (BMI) in the fen-PAH group, as compared with the I/FPAH group. The absolute value of the distance walked at the 6MWT was higher in the I/FPAH group. Nevertheless, to avoid a possible effect of sex in the data, the relative value of the 6MWT (as compared with the predicted value) was measured and no significant difference was found between the fen-PAH and I/FPAH groups. The median duration of fenfluramine-derivative use was 6 months and the median interval between the use of the appetite suppressant and the beginning of symptoms was 4.5 yrs.

Haemodynamic data (table 2) can be compared with previous studies on PAH [24, 25]. The haemodynamic pattern was similar in both groups. Interestingly, the proportion of patients that presented a positive response at the acute vasodilator challenge $(8.3 \%$ in the fen-PAH group and $12.1 \%$ in the I/ FPAH group) was not statistically different and was in agreement with that described in other studies of patients with IPAH [26].

During the time-frame evaluated in the present study, a clear relationship could be attributed to fenfluramine use in France.
The diagnosis of fen-PAH increased up to $\sim 30 \%$ of all cases diagnosed with PAH (considering only IPAH, FPAH and fenPAH) in the period 1995-1996 and started decreasing after 1997 (fig. 1). This was even more striking in females, who represented the majority of fen-PAH patients.

The presence of $B M P R 2$ mutations was evaluated in 40 patients. In total, nine patients presented BMPR2 mutations, including two sisters and seven apparently sporadic cases (BMPR2 mutations were found in $22 \%$ of the 40 studied cases, and $18 \%$ of the 38 sporadic cases). This result reinforces the data previously described by HUMBERT et al. [21] in fen-PAH and THOMSON et al. [27] in IPAH. Interestingly, the duration of exposure to fenfluramine derivatives was significantly lower in patients with BMPR2 mutation (fig. 2).

The median survival of the present cohort was 6.4 yrs. Overall, survival of patients with fen-PAH did not differ from the survival of the I/FPAH patients evaluated in the present authors' service during the same time-frame (historical control; fig. 3).

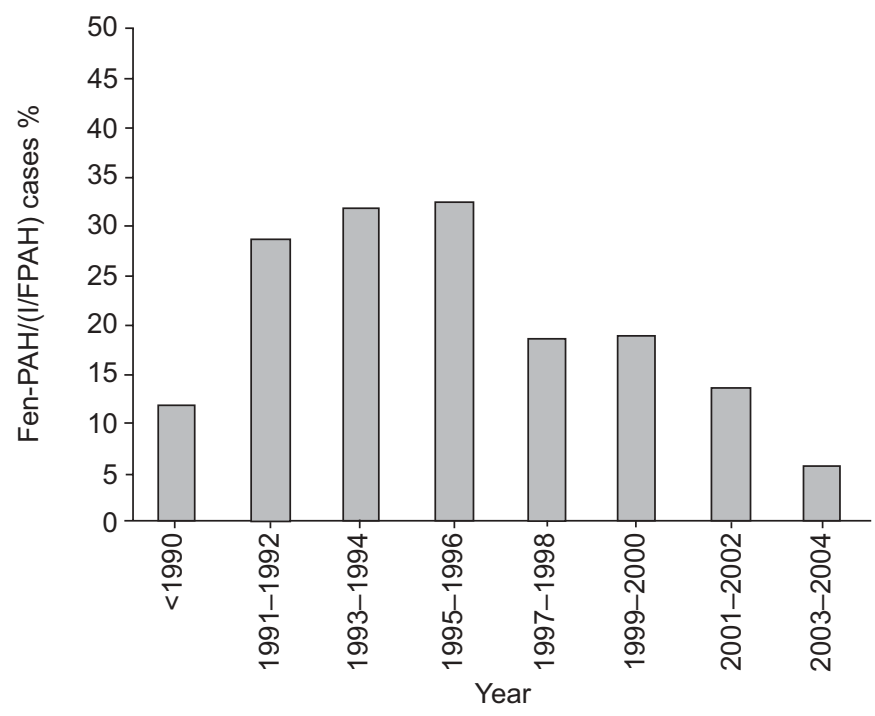

FIGURE 1. Percentage of newly-diagnosed fenfluramine-associated pulmonary arterial hypertension (fen-PAH) patients compared with idiopathic and familia PAH (I/PAH) patients through time. 


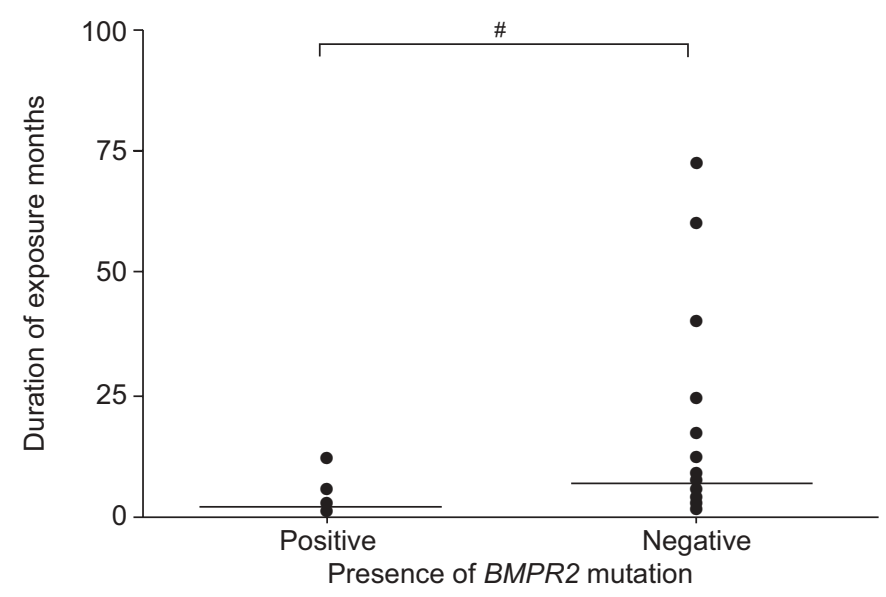

FIGURE 2. Comparison of exposure time for appetite-suppressant-related pulmonary arterial hypertension patients with and without bone morphogenetic protein receptor $(B M P R)$ type 2 mutation. —: median. ${ }^{*}: \mathrm{p}=0.007$.

In order to establish potential prognostic factors, baseline clinical, functional and haemodynamic variables for univariate analysis of survival were selected. As described for IPAH, functional class assessment at baseline is related to overall survival (fig. 4). The 6MWT and selected haemodynamic variables (cardiac index, right atrial pressure and pulmonary vascular resistance) were also related to survival, as previously described for IPAH. It is noteworthy that the duration of fenfluramine use was not related to survival (Table 3). A multivariate analysis including the NYHA functional class, the $6 \mathrm{MWT}$, cardiac index and right atrial pressure, revealed the cardiac index as the only independent prognostic marker in the present cohort of patients, with a hazard ratio $(95 \% \mathrm{CI})$ of 0.278 (0.135-0.574; $\mathrm{p}=0.001)$.

\section{DISCUSSION}

The present study indicates that fen-PAH has a clinical course comparable that of IPAH and FPAH, thus confirming that fenfluramine intake may be considered a risk factor, but it does not result in a different outcome. Also, the temporal relationship of fenfluramine use and PAH strengthens the previous findings on this association.

Baseline clinical and functional characteristics of the present cohort of fen-PAH patients, except for the higher proportion of female patients and higher BMI, were not different from those of the I/FPAH group and could be compared with previously published studies of IPAH patients [28, 29]. The higher proportion of female patients could be probably associated to the sex-related behaviour towards weight loss, where females tend more to adopt weight control measures, including the use of specific pharmacological therapies [30], while the higher BMI should be expected when fenfluramine derivatives were primarily prescribed as appetite suppressants for the treatment of obesity. Of note, ABENHAIM et al. [10] considered whether the association between the use of appetite suppressants and PAH could be explained by the confounding effect of obesity or that of any hidden factor associated with obesity. In the IPPHS study [10], the odds ratio for anorexic agents was similar whether or not the logistic regression models were adjusted for

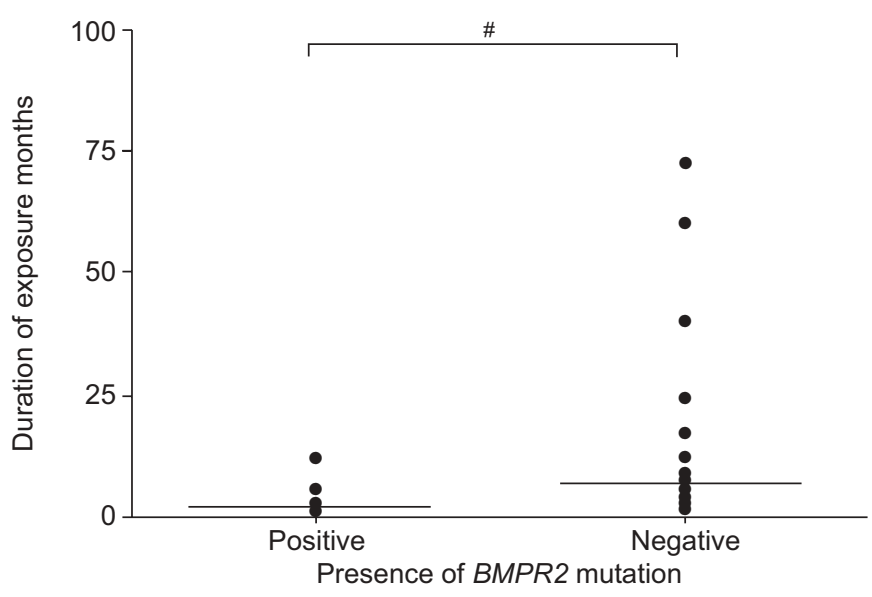

FIGURE 3. Cumulative survival of patients with fenfluramine-associated pulmonary arterial hypertension (fen-PAH; .........) and idiopathic and familial (I/P $\mathrm{PAH} ;-$ - . At 0, 24, 48, 72, 96, 120, 144, 168, 192, 216 and 240 months, the number of patients in the I/FPAH group was 496, 298, 163, 104, 57, 24, 13, 6, 4, 3 and 2, respectively, while in the fen-PAH group, it was 109, 64, 40, 26, 17, 10, 6, 4 2, 1 and $0 .{ }^{*}: p=0.3$, log-rank.

high BMI. The odds ratio for the interaction between obesity and appetite-suppressant use was 1.0 (95\% CI, 0.2--3.5). Therefore, the effect of anorexic agents was the same whether patients had a high BMI or not [10]. Neither weight loss behaviour of another type nor the use of thyroid extracts were positively associated with the risk of primary pulmonary hypertension, as would have been expected if obesity accounted for the odds ratio observed for anorexic agents.

The median duration of fenfluramine derivatives-intake in the present study was of 6 months with a median time between exposure and onset of symptoms of $4.5 \mathrm{yrs}$. It has been shown that the use of appetite suppressants for $>3$ months increased the odds ratio for PAH up to 23.1 [10]. Although it might be associated with the development of the disease, the duration of exposure showed no association with prognosis in the cohort

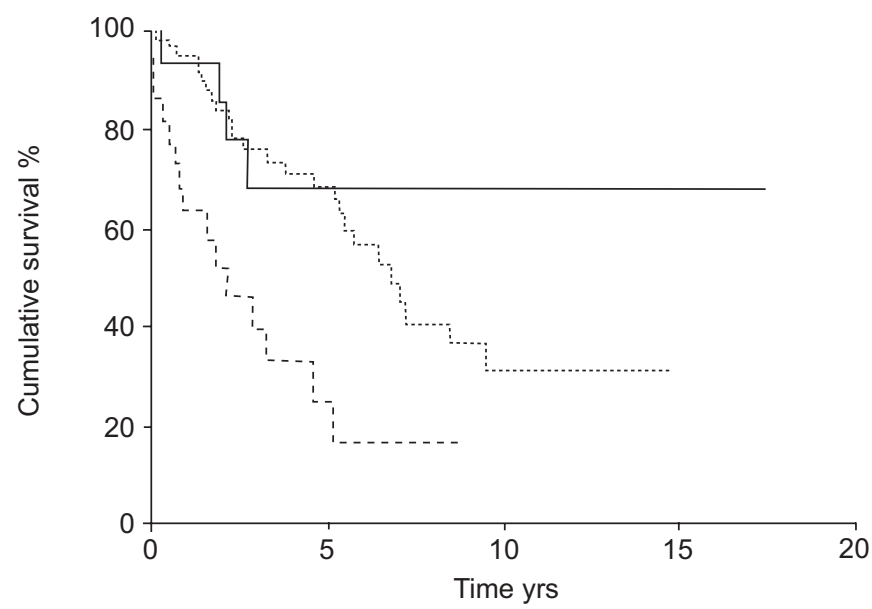

FIGURE 4. Cumulative survival of patients with appetite-suppressant-related pulmonary arterial hypertension according to New York Heart Association functional class $2(-), 3(\cdots \cdots)$ and 4 (---). P=0.0001, log-rank test. 


\begin{tabular}{|c|c|c|c|}
\hline \multirow[t]{2}{*}{ TABLE 3} & \multicolumn{3}{|c|}{$\begin{array}{l}\text { Univariate Cox proportional-hazards analysis of } \\
\text { selected baseline variables }\end{array}$} \\
\hline & & Hazard ratio $(95 \% \mathrm{Cl})$ & $\mathrm{p}$-value \\
\hline \multicolumn{2}{|l|}{ BMI } & $0.960(0.908-1.014)$ & 0.147 \\
\hline \multicolumn{2}{|c|}{$\begin{array}{l}\text { Duration of use of } \\
\text { appetite suppressant }\end{array}$} & $1.004(0.998-1.011)$ & 0.210 \\
\hline \multicolumn{2}{|l|}{ Age } & $1.020(0.990-1.050)$ & 0.191 \\
\hline \multicolumn{2}{|l|}{ 6MWT } & $0.997(0.995-0.999)$ & 0.007 \\
\hline \multicolumn{2}{|l|}{ Pra } & $1.066(1.026-1.108)$ & 0.001 \\
\hline \multicolumn{2}{|l|}{$\mathrm{mPpa}$} & $1.018(0.994-1.042)$ & 0.146 \\
\hline \multicolumn{2}{|l|}{$\mathrm{Cl}$} & $0.340(0.188-0.616)$ & $<0.001$ \\
\hline \multicolumn{2}{|l|}{ PVRi } & $1.037(1.014-1.061)$ & 0.001 \\
\hline \multicolumn{4}{|c|}{ NYHA functional class } \\
\hline \multicolumn{2}{|l|}{$\|$} & $0.448(0.223-0.900)$ & 0.024 \\
\hline \multicolumn{2}{|l|}{ III } & $0.839(0.535-1.314)$ & 0.443 \\
\hline \multicolumn{2}{|l|}{ IV } & $2.659(1.609-4.395)$ & $<0.001$ \\
\hline
\end{tabular}

BMI: body mass index; 6MWT: 6-min walk test; Pra: right atrial pressure; $\mathrm{mPpa}$ mean pulmonary artery pressure; Cl: cardiac index; PVRi: indexed pulmonary vascular resistance; NYHA: New York Heart Association.

in the present study, suggesting, that fenfluramine derivatives may act only as a risk factor for PAH development.

The temporal incidence of fen-PAH at the present authors' centre, in comparison with FPAH and IPAH was clearly related to fenfluramine use in France; in 1995, a severe restriction of fenfluramine use was imposed by health authorities until finally being withdrawn from the global market in 1997. The decreasing incidence observed from the late 1990s provided the temporal and geographic relationship of fenfluramine use and $\mathrm{PAH}$ in the same manner that was previously described with aminorex use [7], thus reinforcing the tendency described in the present authors' previous report [31].

Since only a minority of patients exposed to appetite suppressants develop PAH, the need of other predisposing factors, such as genetic susceptibility, could be postulated, with fenfluramine derivatives acting as a "second hit" in those predisposed subjects. BMPR2 mutations have been described in $>70 \%$ of FPAH cases and $<25 \%$ of patients with IPAH [32]. The presence of BMPR2 mutations in 40 patients (including two sisters and 38 sporadic cases) has been examined and resulted in nine patients with mutated genes $(22.5 \%)$, strengthening the results previously published by HUMBERT et al. [21] and corroborating the concept that fen-PAH shares not only clinical but also genetical predisposition features with IPAH. Interestingly, the duration of exposure in patients with BMPR2 mutation was significantly lower than in patients without the mutation. This is in agreement with the "multiple hit" concept [33], fenfluramine exposure being a trigger/risk factor in genetically predisposed individuals. The proportion of acute vasodilator responders in IPAH and fen-PAH is another feature highlighting the similarities between these two subtypes of PAH patients.

Since the largest prospective cohort of PAH patients published by D'AlONZO et al. [34] in 1991, baseline haemodynamic variables have proved to have prognostic implications in PAH. Even with the development of specific therapies for $\mathrm{PAH}$, the predictive value of baseline haemodynamic evaluation and 6MWT has been confirmed [35]. In the present study, baseline cardiac index, indexed pulmonary vascular resistance, right atrial pressure and 6MWT were associated with survival in the univariate analysis; however, only cardiac index could be identified as an independent prognostic factor in the present cohort of fen-PAH patients. This result has to be scrutinised considering the limitations of the present study, including the small sample enrolled and the different availability of specific treatments for $\mathrm{PAH}$ along the period of observation, which certainly influenced survival and thus possibly impaired extrapolation of the multivariate model.

In order to avoid the impact that the different treatment regimens could impose to the survival estimation in the present study, the fenfluramine-associated pulmonary arterial hypertension group and the group of idiopathic and familial pulmonary arterial hypertension groups were compared during the same time-frame at the present authors' centre. There was no significant difference in survival between the two groups, reinforcing the idea that fenfluramine intake was indeed a risk factor for pulmonary arterial hypertension that did not confer further prognostic influence to the group of patients in terms of overall survival. Fenfluramine-associated pulmonary arterial hypertension shares clinical, functional, haemodynamic and genetic features with idiopathic pulmonary arterial hypertension, as well as the same overall survival. The present authors therefore conclude that fenfluramine exposure characterises a potent trigger for pulmonary arterial hypertension without influencing its clinical course.

\section{REFERENCES}

1 Humbert M, Sitbon O, Simonneau G. Treatment of pulmonary arterial hypertension. N Engl J Med 2004; 351: 1425-1436.

2 Eddahibi S, Morrell N, d'Ortho MP, Naeije R, Adnot S. Pathobiology of pulmonary arterial hypertension. Eur Respir J 2002; 20: 1559-1572.

3 Perros F, Dorfmüller P, Humbert M. Current insights on the pathogenesis of pulmonary arterial hypertension. Semin Respir Crit Care Med 2005; 26: 355-364.

4 Trembath RC, Harrison R. Insights into the genetic and molecular basis of primary pulmonary hypertension. Pediatr Res 2003; 53: 883-888.

5 Gurtner HP. [Chronic pulmonary hypertension of vascular origin, plexogenic pulmonary arteriopathy and the appetite depressant aminorex: addenda to an epidemic.]. Schweiz Med Wochenschr 1985; 115: 782-789.

6 Gurtner HP. Aminorex and pulmonary hypertension. A review. Cor Vasa 1985; 27: 160-171.

7 Loogen F, Worth H, Schwan G, Goeckenjan G, Lösse B, Horstkotte D. Long-term follow-up of pulmonary hypertension in patients with and without anorectic drug intake. Cor Vasa 1985; 27: 111-124.

8 Douglas JG, Munro JF, Kitchin AH, Muir AL, Proudfoot AT. Pulmonary hypertension and fenfluramine. Br Med J (Clin Res Ed) 1981; 283: 881-883. 
9 Brenot F, Herve P, Petitpretz P, Parent F, Duroux P, Simonneau G. Primary pulmonary hypertension and fenfluramine use. Br Heart J 1993; 70: 537-541.

10 Abenhaim L, Moride Y, Brenot F, et al. Appetite-suppressant drugs and the risk of primary pulmonary hypertension. International Primary Pulmonary Hypertension Study Group. N Engl J Med 1996; 335: 609-616.

11 Eddahibi S, Adnot S. Anorexigen-induced pulmonary hypertension and the serotonin (5-HT) hypothesis: lessons for the future in pathogenesis. Respir Res 2002; 3: 9.

12 Hervé P, Launay JM, Scrobohaci ML, et al. Increased plasma serotonin in primary pulmonary hypertension. Am J Med 1995; 99: 249-254.

13 Eddahibi S, Humbert M, Fadel E, et al. Hyperplasia of pulmonary artery smooth muscle cells is causally related to overexpression of the serotonin transporter in primary pulmonary hypertension. Chest 2002; 121: Suppl. 3, 97S-98S.

14 Eddahibi S, Humbert M, Fadel E, et al. Serotonin transporter overexpression is responsible for pulmonary artery smooth muscle hyperplasia in primary pulmonary hypertension. J Clin Invest 2001; 108: 1141-1150.

15 Rich S, Rubin L, Walker AM, Schneeweiss S, Abenhaim L. Anorexigens and pulmonary hypertension in the United States: results from the surveillance of North American pulmonary hypertension. Chest 2000; 117: 870-874.

16 Rich S, Shillington A, McLaughlin V. Comparison of survival in patients with pulmonary hypertension associated with fenfluramine to patients with primary pulmonary hypertension. Am J Cardiol 2003; 92: 1366-1368.

17 Simonneau G, Galiè N, Rubin LJ, et al. Clinical classification of pulmonary hypertension. J Am Coll Cardiol 2004; 43: 5S-12S.

18 Guyatt GH, Sullivan MJ, Thompson PJ, et al. The 6-minute walk: a new measure of exercise capacity in patients with chronic heart failure. Can Med Assoc J 1985; 132: 919-923.

19 Sitbon O, Humbert M, Jaï X, et al. Long-term response to calcium channel blockers in idiopathic pulmonary arterial hypertension. Circulation 2005; 111: 3105-3111.

20 Deng Z, Morse JH, Slager SL, et al. Familial primary pulmonary hypertension (gene PPH1) is caused by mutations in the bone morphogenetic protein receptor-II gene. Am J Hum Genet 2000; 67: 737-744.

21 Humbert M, Deng Z, Simonneau G, et al. BMPR2 germline mutations in pulmonary hypertension associated with fenfluramine derivatives. Eur Respir J 2002; 20: 518-523.

22 Sitbon O, Humbert M, Nunes H, et al. Long-term intravenous epoprostenol infusion in primary pulmonary hypertension: prognostic factors and survival. J Am Coll Cardiol 2002; 40: 780-788.

23 McLaughlin VV, Shillington A, Rich S. Survival in primary pulmonary hypertension: the impact of epoprostenol therapy. Circulation 2002; 106: 1477-1482.

24 McLaughlin VV, Sitbon O, Badesch DB, et al. Survival with first-line bosentan in patients with primary pulmonary hypertension. Eur Respir J 2005; 25: 244-249.

25 Souza R, Bogossian HB, Humbert M, et al. N-terminal-probrain natriuretic peptide as a haemodynamic marker in idiopathic pulmonary arterial hypertension. Eur Respir J 2005; 25: 509-513.

26 Costa EL, Jardim C, Bogossian HB, Amato MB, Carvalho CR, Souza R. Acute vasodilator test in pulmonary arterial hypertension: evaluation of two response criteria. Vascul Pharmacol 2005; 43: 143-147.

27 Thomson JR, Machado RD, Pauciulo MW, et al. Sporadic primary pulmonary hypertension is associated with germline mutations of the gene encoding BMPR-II, a receptor member of the TGF- $\beta$ family. J Med Genet 2000; 37: 741-745.

28 Humbert M, Sitbon O, Chaouat A, et al. Pulmonary arterial hypertension in France: results from a national registry. Am J Respir Crit Care Med 2006; 173: 1023-1030.

29 McLaughlin VV, Oudiz RJ, Frost A, et al. Randomized study of adding inhaled iloprost to existing bosentan in pulmonary arterial hypertension. Am J Respir Crit Care Med 2006; 174: 1257-1263.

30 Patel MR, Donahue M, Wilson PW, Califf RM. Clinical trial issues in weight-loss therapy. Am Heart J 2006; 151: 633-642.

31 Simonneau G, Fartoukh M, Sitbon O, Humbert M, Jagot JL, Hervé P. Primary pulmonary hypertension associated with the use of fenfluramine derivatives. Chest 1998; 114: 195S199S.

32 Humbert M, Trembath RC. Genetics of pulmonary hypertension: from bench to bedside. Eur Respir J 2002; 20: 741-749.

33 Yuan JX, Rubin LJ. Pathogenesis of pulmonary arterial hypertension: the need for multiple hits. Circulation 2005; 111: 534-538.

34 D'Alonzo GE, Barst RJ, Ayres SM, et al. Survival in patients with primary pulmonary hypertension. Results from a national prospective registry. Ann Intern Med 1991; 115: 343-349.

35 Jing Z, Sitbon O, Souza R, Jaïs X, Humbert M, Simonneau G. Survival of patients with pulmonary arterial hypertension (PAH) diagnosed at 3 different time periods. Proc Am Thorac Soc 2006; 3: A729. 